\title{
Network Coordination, Self-Regulation Mode, and Autonomous Control Space Planning of Microgrid
}

\author{
Wenyao Sun, Youwen Tian (D), and Jiannan Li \\ Collage of Information and Electrical Engineering, Shenyang Agricultural University, Shenyang 110866, China \\ Correspondence should be addressed to Youwen Tian; youwen_tian395@163.com
}

Received 21 July 2020; Revised 21 September 2020; Accepted 22 October 2020; Published 17 November 2020

Academic Editor: Yang Li

Copyright ( $\odot 2020$ Wenyao Sun et al. This is an open access article distributed under the Creative Commons Attribution License, which permits unrestricted use, distribution, and reproduction in any medium, provided the original work is properly cited.

\begin{abstract}
This paper investigates the network coordination, self-regulation mode, and autonomous control spatial planning of microgrid. To do this, the cooperative self-discipline model of multi-microgrid intelligent distribution network is constructed. Based on combing the power control of multi-microgrid with high penetration situation, the concept and characteristics of distribution network and self-regulation mode are defined according to the new requirements, and the basic framework and decision-making process of self-regulation mode are put forward. Further, the formulation method of autonomous spatial planning for multimicronetworks is described. By constructing cooperative self-discipline space scheme and its reward and punishment mechanism, the network operation behavior is restrained and guided, and the control dimension of the distribution network is reduced. Finally, a typical case is given to illustrate the effectiveness of cooperative self-discipline supervision mode in reducing the spacetime dimension of distribution network supervision.
\end{abstract}

\section{Introduction}

The impact of multi-microgrid high-permeability grid connection on distribution managers not only stays at the physical level such as the traditional trend direction, size changes, and node voltage changes, and the network reconstruction and reactive power optimization caused by it [1-4]. The solution is not only the optimization goal of the distribution network when multiple grids are connected to the grid and an optimal scheduling algorithm that seeks a global optimal solution [5-7]. The diversified development trend of multi-microgrid's energy types, increase in power supply, energy storage capacity, and electric vehicle access makes it more demanding to participate in distribution network operation and management in the future. This kind of interest appeal not only stays at the physical level and component level but also manifests itself in: How does the multi-micronetwork, as the main body of competition, participate in the distribution network management and service? The different roles of microgrids in the power distribution system will affect the control mechanism and operation mode of the entire power distribution system and promote the emergence of new forms, new formats, and new mechanisms in the power distribution system [8-10]. Therefore, the diversified models, diverse service demands, and diverse service forms will make the power supply network more flexible and complex. How to allocate and control depends on the commodity exchange/transaction behavior with the main objective as the benefit, the operation/regulation behavior with the main objective of physical system security and quality control, and the social interaction with the main objective of information interaction and confidentiality or wisdom improvement sharing behavior [11-13]. According to different operating conditions, due to the "ground" measures, the use of different control modes will be an issue that needs to be solved during the operation of the distribution network and multimicrogrid [14-18].

The large-scale development and high penetration of microgrids will change the traditional power distribution pattern, and the distribution network functions will shift from load management to multi-microgrid collaborative control to adapt to the multi-microgrid and multiformat development trend [8-19]. This paper considers that the 
intelligent distribution system's management and control of multi-micronet operation can neither allow it to be fully autonomous and plug-and-play nor can it fully imitate the direct regulation mode of the large network [20-22]. The main function of the distribution manager should be changed to the distribution network [23-25]. The rational allocation of resources reconciles the contradiction between multiple microgrid power generation activities competing for distribution network resources, creating a fair environment and a good service system for its operation [26-28].

As an intelligent subsystem in the power distribution network or smart distribution network, microgrid has the characteristics of high autonomy and friendly interaction [29]. The operation behavior of microgrid should be restricted and restricted to cooperate with the safety and economic operation goals of the power distribution network [30]. At the same time, the microgrid should also maximize its own benefits within the allowed operating range. In other words, a new type of collaborative self-regulatory relationship needs to be established between the distribution network and the microgrid [31, 32].

This paper makes innovations in the following three aspects:

(1) Based on the existing distribution automation system, the cooperative self-discipline model designed in this paper will build a new framework system to meet the development and implementation requirements of various information intelligent processing based on cooperative strategy and flexible power generation interval.

(2) Under the condition of normal and autonomous operation of microgrid, its energy management system monitors, identifies, and judges whether it meets the requirements of distribution network or adjacent microgrid after receiving autonomous spatial planning. In case of critical or cross-border situation, typical cross-border characteristic data should be extracted, and the operating point of microgrid should be relocked within a strict range as soon as possible.

(3) In the new framework, the elastic self-discipline space is constructed and revised, and a new type of cooperative relationship is established, which can create a larger operation area for the high penetration of multi-microgrid and reduce the difficulty and operation cost of managing and controlling the distribution network.

\section{Framework System of Cooperative Self- Regulatory Control Mode for Distribution Network}

The concept of cooperative self-regulatory regulation mode in the distribution network includes two meanings of "selfregulation" and "coordination." "Self-discipline" is targeted at microgrids. The distribution network can restrain and guide the operation behavior of multiple microgrids by formulating the planning of microgrid autonomous power generation interval (autonomous operation area, coordinated control area, and restricted area). Based on the "selfdiscipline" of microgrid, it provides a technical basis for reducing the control dimension and control time of the grid. The "collaborative" management and control model adopted by the distribution network includes both centralized and distributed specific technical measures. The establishment of a cooperative and self-regulatory regulatory model has promoted the mutual benefit and win-win situation of micronets and distribution networks, micronets, and micronets in an environment of mutual tolerance and selfrestraint.

How to deal with the relationship between microgrids and distribution networks is a question of whether the two have evolved into constraints or supporters of mutual interest. If the distribution network is more based on its own operation and requires many restrictive and strong control measures (nonactive distribution management methods) for each microgrid, it will inevitably severely restrict the potential of multi-microgrids to absorb renewable clean energy. If each microgrid requires the distribution network to fully cooperate with its pursuit of maximizing energy management benefits (completely active distribution services), it will inevitably significantly increase the overall cost of distribution network investment, capacity expansion, regulation, and control and ultimately affect more load users. Eventually, it will affect the electricity charges of more users. Therefore, it is not the smartest move to deal with the relationship between the microgrid and the distribution network in a nonactive or fully proactive manner. A new balance of interests needs to be found between the two extreme methods to build the microgrid and the distribution network together.

Under the collaborative self-regulatory mode, the functional attributes of the distribution network and microgrid have changed. It is necessary to build a new framework system based on the existing distribution automation system to adapt to a variety of information intelligent processing based on collaborative strategies and flexible power generation intervals development and implementation needs (see Figure 1).

The distribution management system is based on the prediction of the power exchange characteristics of the microgrid and the distribution network, intelligent application distribution network operation, typical characteristics of the microgrid, higher-level grid regulation requirements or instructions, adjacent microgrids within the jurisdiction, and power distribution at the same level information such as internetwork communication determines whether the absolute value of the output of each microgrid will be greater than the threshold in the index system. If it is greater, a distribution network operation control event is formed, and the control system formulates as a cooperative self-regulatory control command, including a self-regulatory operation command and a cooperative control command.

The directive formulates and issues an autonomous space plan that regulates and guides the operation behavior of each microgrid and forms a related control plan for the distribution network. Each microgrid and distribution network arranges 


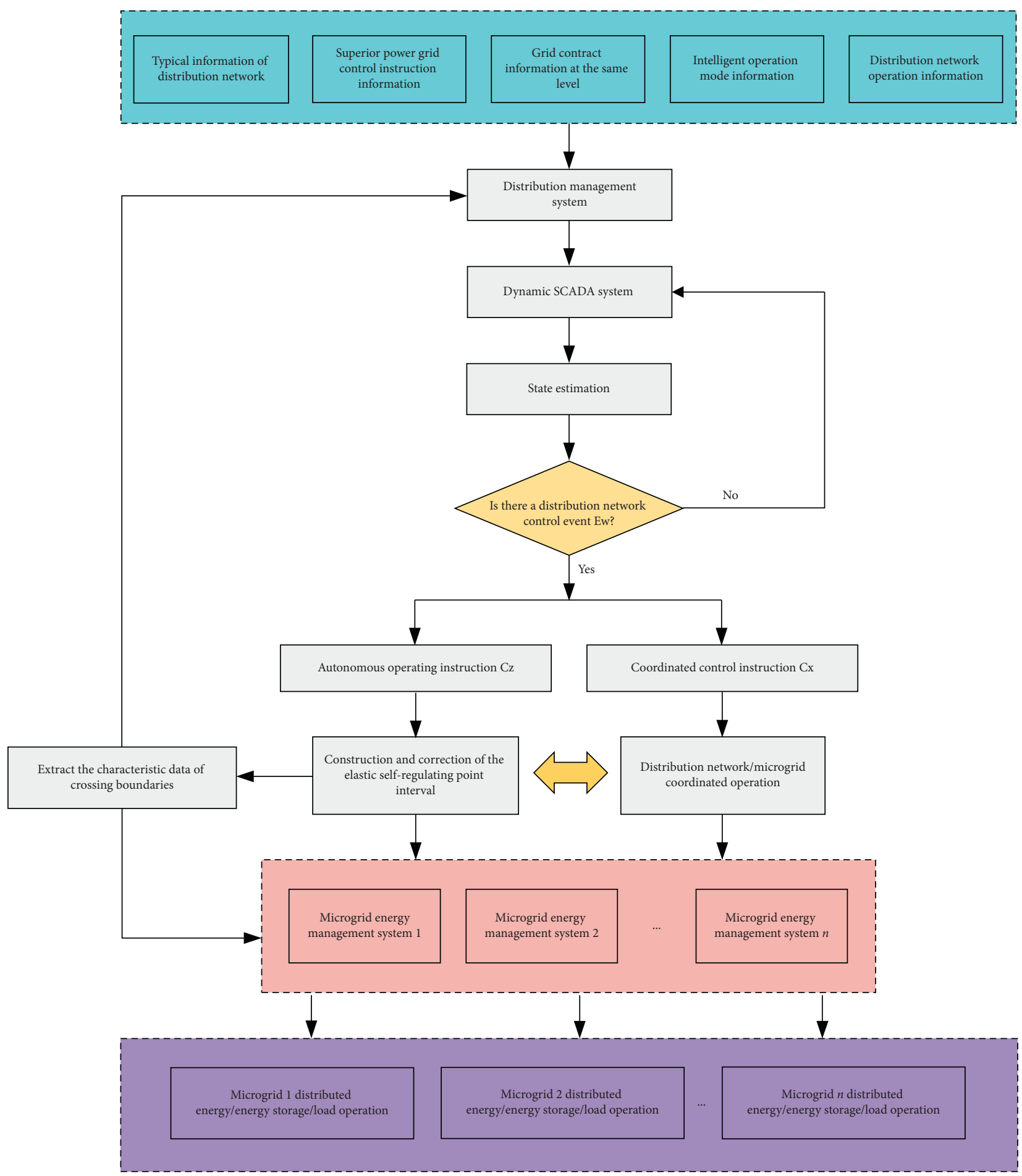

FIGURE 1: Framework of the operation and control mode of coordination and self-disciplinary.

the operation mode according to the above plan. During the execution of the operation mode, the distribution management system focuses on the determination of responsibilities and rewards and punishments after the ultra-autonomous space operation of the microgrid according to the actual operation of the distribution network and the microgrid or online estimation information. Interval and distribution network control strategies are corrected (see Figure 2).
Under the condition of normal autonomous operation of microgrid, its energy management system monitors and identifies the operation behavior of its internal source library after receiving the autonomous spatial planning and judges whether it meets the requirements of distribution network or adjacent microgrid. In case of emergency or cross-border situation, typical cross-border characteristic data should be extracted, and measures such as adjusting the DG/DR 


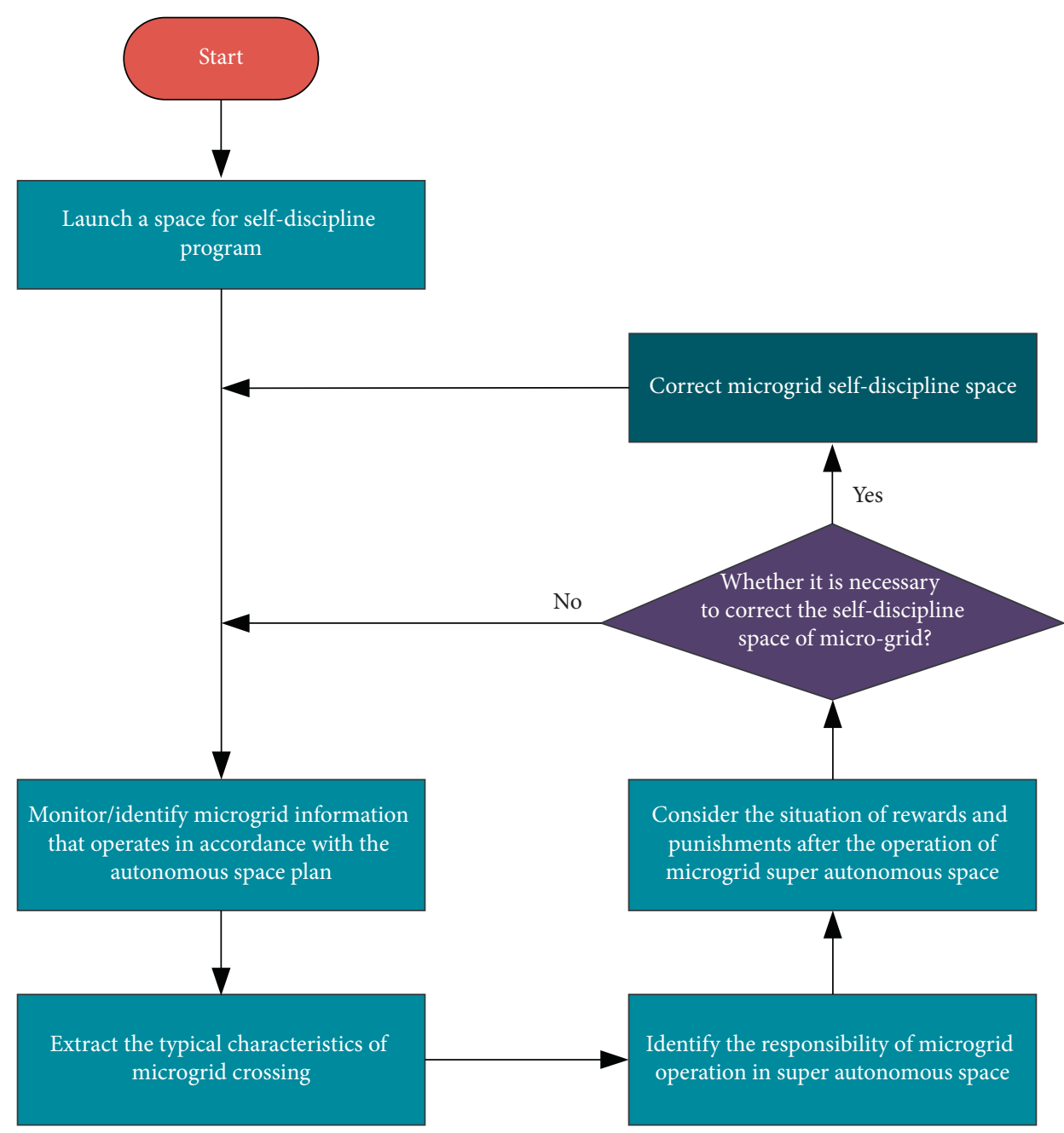

Figure 2: Develop and calibrate the self-disciplinary space planning process for distribution systems.

operation mode, switching charging and discharging modes of energy storage devices, or intelligently managing charging and discharging behaviors should be taken to lock the operating point of microgrid as soon as possible. Within the specified range, the microgrid realizes self-disciplined operation decision (see Figure 3).

In the framework of the designed cooperative self-regulatory regulation model, the distribution management system works through the formulation of a distribution network/ microgrid collaborative regulation strategy and the construction and correction of an elastic self-regulatory space, between the distribution management system and the multimicrogrid energy management system. A new type of collaborative relationship has been established, which can reduce the difficulty in managing and controlling the distribution network and the operating cost while creating a larger operating area for high penetration of multi-micronetworks.

\section{Multi-Microgrid Self-Regulatory Power Generation Interval Planning}

3.1. Multi-Microgrid Self-Regulatory Power Generation Interval Plan Formulation Process. First, the power distribution management system divides the daily power generation behavior of the multi-microgrid into several time scales based on information such as the load characteristic curve data of the area under its jurisdiction and the superior grid and formulates typical scenarios such as peaks and valleys. Secondly, each microgrid energy management system estimates and reports the upper and lower limits of the daily power consumption planning interval in a typical scenario formulated by the power distribution management system based on its own power generation and consumption capacity. Then, the power distribution management system sorts the power generation rights of each microgrid based on the confidence evaluation results of the historical power generation behavior data of the microgrid under its jurisdiction and at the same time estimates the allocated power generation space. Finally, the distribution manager takes into account the instructions of the upper-level power grid for peak and frequency regulation, as well as the microgrid operating characteristics and the interrelationship between multiple microgrids, reasonably dispatches the distribution control resources, and formulates and releases to guide and regulate the microgrid. The self-disciplined space plan for power generation behavior can be expressed in the form of 


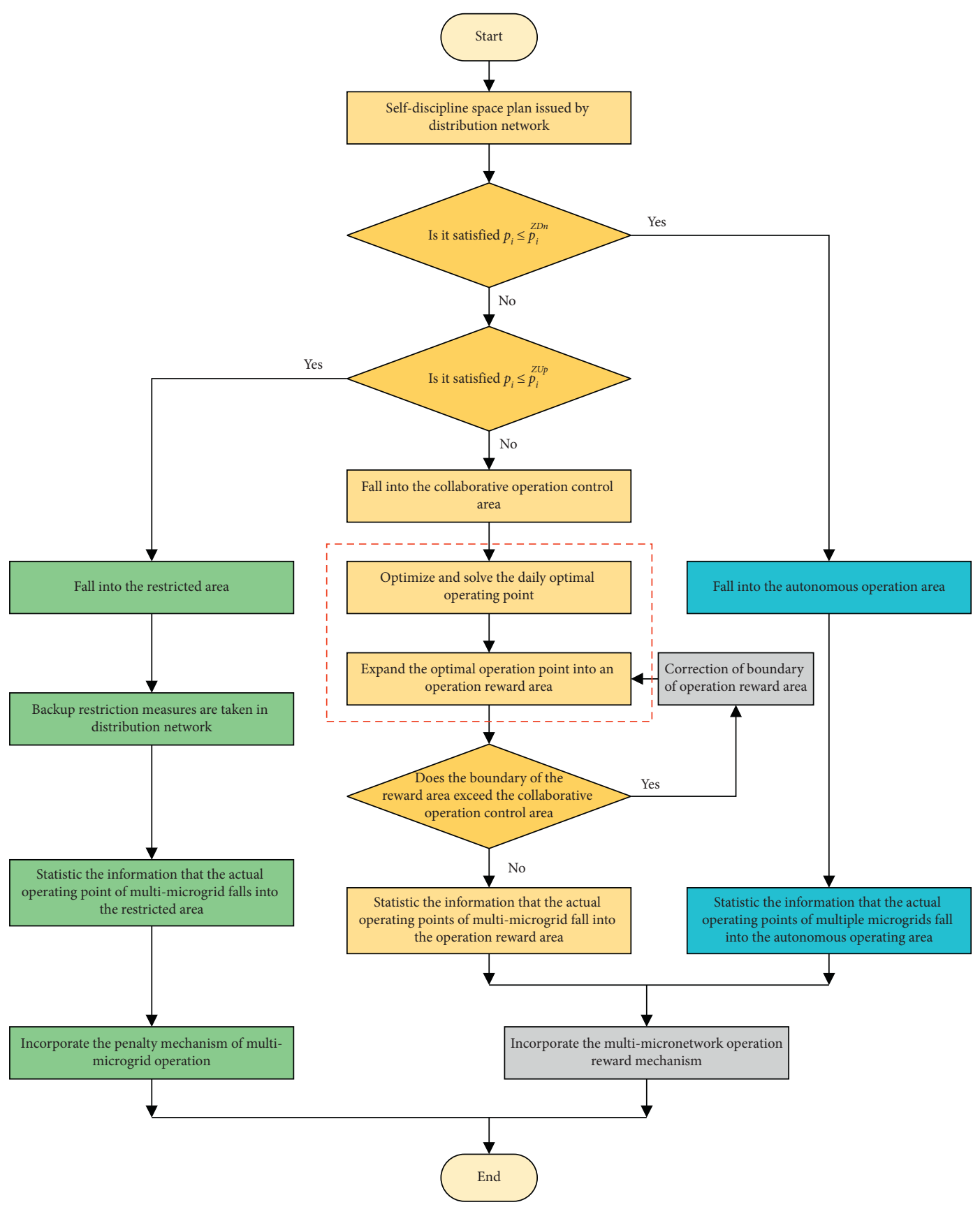

FIGURE 3: Flowchart of self-disciplinary operation of microgrids.

intervals with different degrees of restraint, such as the selfdiscipline operating area, cooperative control area, and restricted area.

The specific steps for making a self-regulatory running space are as follows:

Step 1: the distribution management system divides the time scale and formulates a typical scenario (see Figure 4).

In a typical day, the power distribution management system divides the representative time scenarios $\Delta t_{1} \longrightarrow \Delta t_{n}$ (such as peaks and valleys) according to the power-time characteristics according to the historical information of each microgrid and the historical information of the regional load. In Figures 2-6, each $\Delta t$ corresponds to the case of a typical scenario. The value of $\Delta t$ is related to the actual daily conditions and the specific configuration of the microgrid. The power distribution management system issued the divided typical time scenario $\Delta t_{1} \longrightarrow \Delta t_{n}$ to the micronets under its jurisdiction a few days ago as the basis for the predictive power generation interval of each micronet.

Step 2: each microgrid forecasts the power generation interval. 


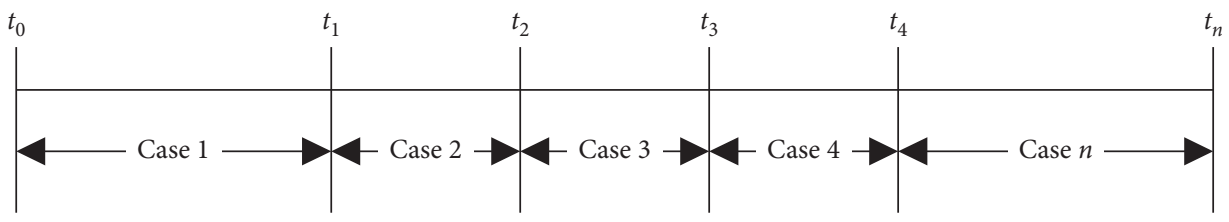

FIgURE 4: Typical timing scenario.

Based on their own power generation and consumption characteristics, energy storage configuration, and cost information, each microgrid reports the daily net power generation interval forecast data in the time scenario divided by the distribution management system: $\quad \Delta t_{1} \longrightarrow\left[P_{i}^{\mathrm{Dn}}, P_{i}^{\mathrm{Up}}\right], \Delta t_{2} \longrightarrow\left[P_{i}^{\mathrm{Dn}}, P_{i}^{\mathrm{Up}}\right], \ldots$, $\Delta t_{n} \longrightarrow\left[P_{i}^{\mathrm{Dn}}, P_{i}^{\mathrm{Up}}\right]$.

Among them, $\left[P_{i}^{\mathrm{Dn}}, P_{i}^{\mathrm{Up}}\right]$ represents the upper and lower limits of the net active power output of microgrid $i$ during the period.

Step 3: according to the historical output confidence of the microgrid, the proportion of clean energy, and the cause of power flow blockage, when the distribution network has limited allocated resources, the power generation order obtained by the microgrid is formed. In this mode, the microgrid energy management system predicts the accuracy of its own power generation and consumption behavior, and the proportion of clean energy in total power generation will directly affect the right ranking when micronetworks compete for resources when the distribution network resources are limited.

Step 4: the distribution management system estimates the allocated active power interval.

Assume that the demand for active power (except the microgrid's own load) in a local area during the $\Delta t$ period is $P_{L} \in\left[P_{L}^{\mathrm{Dn}}, P_{L}^{\mathrm{Up}}\right]$, where $\left[P_{L}^{\mathrm{Dn}}, P_{L}^{\mathrm{Up}}\right]$ represents the possible distribution interval of active demand at a certain probability. Then, the active demand PL during this period is the power space that the distribution network can allocate to the microgrid.

Step 5: distribution management system develops and issues a self-regulatory space plan.

In the time scenario $\Delta t$ divided in Step 1, for different situations, explain the process of making a self-regulatory space plan.

Case 1: if $\sum_{i=1}^{n} P_{i}^{\mathrm{Up}}<206 P_{L}$, then supply is less than demand. In this case, the upper limit of the net active power reported on all micronets is less than the active load demand of the distribution network. The output upper limit cannot be reduced when the load flow rate constraint condition of the branch is satisfied. If the load rate constraint is exceeded, the reported maximum net output of active power will be reduced to some extent.

Case 2: if $\sum_{i=1}^{n} P_{i}^{\mathrm{Up}}>212 P_{L}$, then supply exceeds demand.

In this case, the upper limit of the net active power reported on all micronets is greater than the active load demand of the distribution network. The net power generation interval reported on each micronet needs to be reduced according to the satisfaction index to maintain supply and demand balance.

According to the above two typical situations, the distribution management system formulates a selfregulatory space plan, including a self-regulatory operating area, a cooperative control area, and a restricted area (see Figure 5).

3.1.1. Self-Regulatory Area. The microgrid can operate in a completely autonomous manner without restriction in the autonomous operating zone. The boundary $P_{i}^{Z D n}$ of the microgrid $i$ self-discipline operating area can be formulated according to the lower boundary $P_{i}^{\mathrm{Dn}}$ of the prediction interval reported by each microgrid, that is, $P_{i}^{\mathrm{ZDn}}=P_{i}^{\mathrm{Dn}}$. It should be pointed out that although there is less net power generation in the microgrid at this time, it does not affect the safety of the distribution network, but the increase in power purchase by the distribution network from the higher-level grid will cause the overall economic cost indicators to deteriorate. Therefore, there is a possibility that the distribution network will increase the lower boundary of $P_{i}^{\mathrm{Dn}}$ of the forecast interval reported on the micronetwork to ensure its own economic operation, the amount of upregulation is $\Delta P_{i}^{\mathrm{Dn}}$, and at this time $P_{i}^{\mathrm{ZDn}}$ is the sum of $P_{i}^{\mathrm{Dn}}$ and $\Delta P_{i}^{\mathrm{Dn}}$

3.1.2. Restricted Area. The restricted area strictly stipulates the upper limit of the operation boundary of each microgrid. The microgrid-level energy management system needs to introduce this mandatory constraint into its regulation strategy when it performs internal control. When the failure of the microgrid control exceeds the restricted area, the distribution network has the right to take backup restrictions in accordance with the agreement. $P_{i}^{\mathrm{Up}}$ is the upper bound of prediction interval in microgrid $i$. If it meets Case $1, P_{i}^{\mathrm{ZUp}}=P_{i}^{\mathrm{Up}}$. If it meets Case 2, you need to lower the upper boundary $P_{i}^{\mathrm{Up}}$ of the prediction interval reported by microgrid by $\Delta P_{i}^{\mathrm{Up}}$. Then, $P_{i}^{\mathrm{ZUp}}$ is the difference between $P_{i}^{\mathrm{Up}}$ and $\Delta P_{i}^{\mathrm{Up}}$.

3.1.3. Coregulatory Region. For microgrids operating in the coordinated control area, although there is no risk of physically damaging the security of the distribution network, there is a correlation in the competition for distribution network resources and interests. The distribution network needs to adopt coordinated control measures. In accordance with the changing operating scenarios, the 


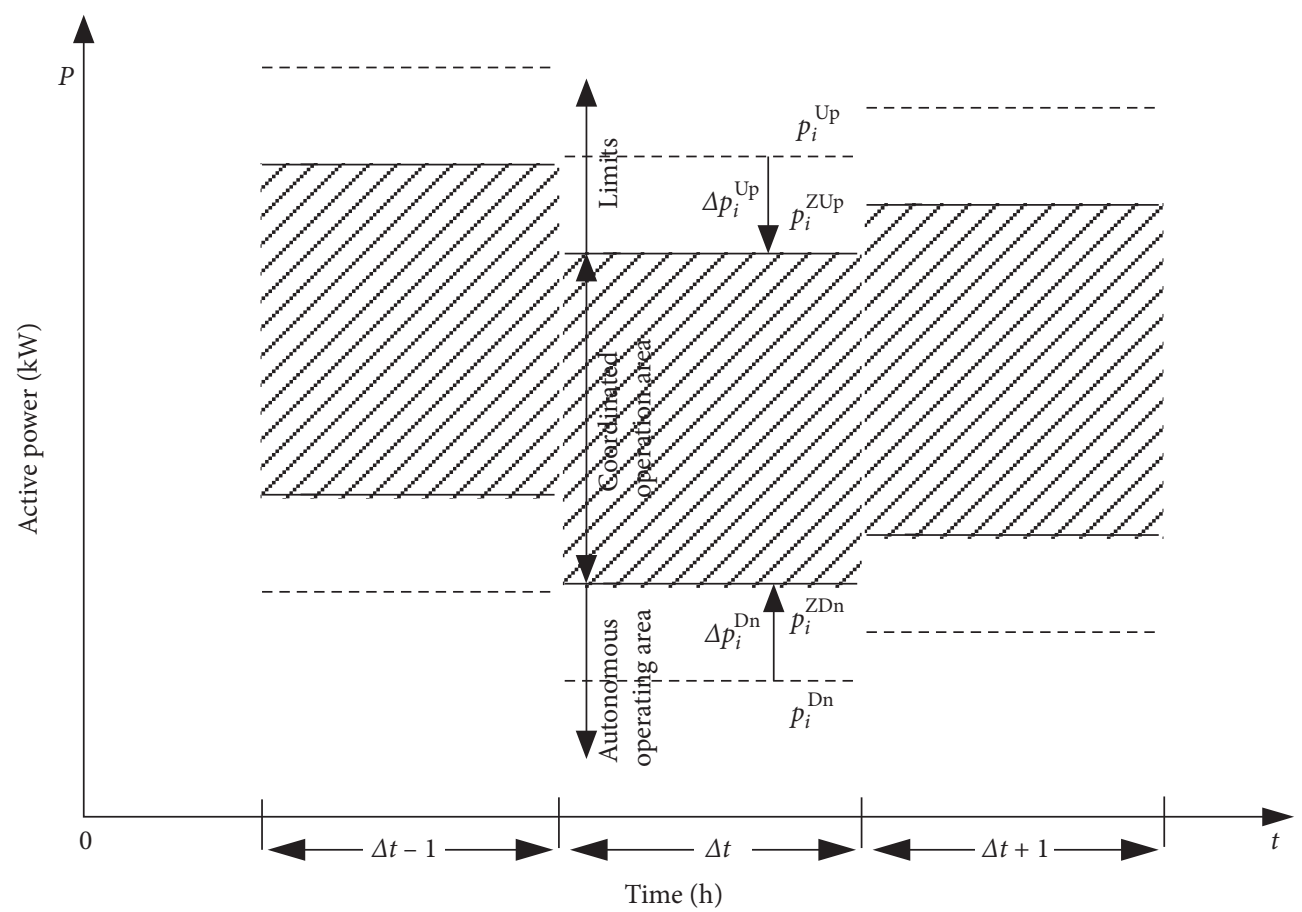

FIGURE 5: Schematic diagram of self-disciplinary space planning.

coordinated control zone is used to define the operating subintervals based on the fair distribution of the win-win space of the interests of all parties. The upper and lower limits of the microgrid $i$ cooperative control zone are taken to be the boundaries of the restricted zone and the boundaries of the autonomous operating zone, namely, $P_{i}^{\mathrm{ZUp}}$ and $P_{i}^{\mathrm{ZDn}}$.

In summary, the key to the self-regulatory space plan of the distribution management system is to formulate a model to solve the upper and lower boundaries of the cooperative operation control area, especially the upper boundary $\Delta P_{i}^{\mathrm{Up}}$.

\subsection{Method for Making Multi-Microgrid Self-Regulated Op-} eration Space Plan. As can be seen from the previous section, when there is a conflict between the net power generation demands of multiple microgrids, that is, when supply exceeds demand, the upper limit of the predicted net power generation interval of each microgrid needs to be appropriately reduced; in other words, the effective distribution of the effective resources of the distribution network is fair and reasonable to achieve multilateral satisfaction. From the load demand of the distribution network (excluding the microgrid's own load), the adjustable active power provided by the distribution network, and the upper limit of the active power output predicted by each microgrid, the reduction of the net active power output of each microgrid can be obtained, as shown in the following formula:

$$
P_{\Sigma}^{\mathrm{Up}}=P_{L}+P_{S}-\Delta P_{\Sigma}^{\mathrm{Up}}
$$

Here, the sum of the upper limit of the estimated net active power of the multi-micronetwork is denoted by $P_{\Sigma}^{\mathrm{Up}}$, the overall load demand of the distribution network is represented by $P_{L}, P_{S}$ denotes the adjustable active power in the distribution network through transfer lines, and $\Delta P_{\Sigma}^{\mathrm{Up}}$ denotes the multi-microgrid estimated total reduction in active output cap.

There is a coupling relationship between different micronetworks, and $S_{i, j}$ represents the expected exchange power between the $i$ and $j$ micronetworks. For microgrid 1, its net generation behavior demands $S_{1}$, and the expected exchange power is $S_{1,2}$, which is also applicable to microgrid 2. It can be seen from the following equation:

$$
\begin{aligned}
& S_{1,2}=S_{2}+\frac{\left(U_{1}-U_{2}\right)^{2}}{Z_{12}}, \\
& S_{2,1}=S_{1}-\frac{\left(U_{1}-U_{2}\right)^{2}}{Z_{12}},
\end{aligned}
$$

where $U_{1}, U_{2}$ represent the voltage amplitude of microgrids 1 and $2, Z_{12}$ represents the contact impedance, and $I_{12}$ represents exchange current.

If $S_{1,2}=S_{2,1}$, then both parties expect no conflict; if $S_{1,2} \neq S_{2,1}$, then the optimization objective is expressed as follows:

$$
\min F(X)=\sum_{i=1}^{2}\left\|X-S_{g 1,2}\right\|_{2},
$$


where $S_{g 1,2}=\left[S_{1,2}, S_{2,1}\right] ; F$ is a function of the degree of inconsistency. The optimization model calculated to the general situation is as follows:

$$
\begin{aligned}
\min F_{n}(X) & =\sum_{i=1}^{L}\left\|X-S_{g}\right\|_{2}, \\
\text { s.t. } \quad M_{n} & =\left\{\begin{array}{l}
f_{n}(X) \leq \varepsilon_{n}, \\
G_{n}(X)=0, \\
H_{n}(X) \leq 0 .
\end{array}\right.
\end{aligned}
$$

The above is the optimal power flow model, where $f_{n}(X) \leq \varepsilon_{n}$ is the generation demand constraint of microgrid; $G_{n}(X)=0$ is the constraint of power flow equation, namely, the equality constraint condition of optimal power flow; $H_{n}(X) \leq 0$ is the inequality constraints of control variables and functions, such as the upper and lower limits of active or reactive power output and node voltage constraints. $\varepsilon \in\left[\varepsilon_{\min }, \varepsilon_{\max }\right]$ is the target satisfaction threshold interval, within which it is considered that there is no crowding between the two microgrid generation intervals.

The reduction model of the active power output of each microgrid needs to be established taking into account the confidence of the historical information of the microgrid, the proportion of the microgrid's clean energy generation capacity, and the determination of responsibility when the line flow is blocked. Among many factors, we should first consider eliminating the problem of distribution network safety caused by line blocking.

When multiple microgrids are connected to the grid, no matter whether the output of the microgrids shows an oversupply or undersupply situation, it is not ruled out that a certain branch or some of the branches will be overloaded or blocked. The sensitivity coefficient method is used to solve the problem of excessive active net output of multimicrogrids. The following constraints should be observed in the power space allocation:

$$
\begin{aligned}
\Delta P_{i} & =P_{G i}-U_{i} \sum_{j \in i} U_{j}\left(G_{i, j} \cos \delta_{i, j}+B_{i, j} \sin \delta_{i, j}\right)-P_{L i}=0, \\
\Delta Q_{i} & =Q_{G i}-U_{i} \sum_{j \in i} U_{j}\left(G_{i, j} \cos \delta_{i, j}+B_{i, j} \sin \delta_{i, j}\right)-Q_{L i}=0 .
\end{aligned}
$$

Here, power active power of node $i$ is represented by $P_{G i}$ and $P_{L i}$ is denoted by load active power of node $i$.

$$
\left\{\begin{array}{l}
U_{i}^{\min } \leq U_{i} \leq U_{i}^{\max }, \\
S_{i} \leq S_{i}^{\max },
\end{array}\right.
$$

where $U_{i}$ and $U_{j}$ are $i$ and $j$ voltage amplitude, respectively; $G_{i, j}$ and $B_{i, j}$ are the real and imaginary parts of the $i$-th and $j$-th elements of the node admittance matrix, respectively; $\delta_{i, j}$ denotes the phase angle difference between voltages at nodes $i$ and $j ; U_{i}^{\min }$ and $U_{i}^{\max }$ are the lowest and uppermost limit voltage amplitude of node $i ; S_{i}$ denotes the transmission power of branch $i$; the maximum transmission power of branch $i$ is represented by $S_{i}^{\max }$.
In the steady-state operation of the distribution network, the relationship between branch power flow and node injected power can be given concisely through the sensitivity analysis method. The branch $k$ power flow can be expressed as follows:

$$
P_{k}=\sum_{i=1}^{n} C_{z s, i} P_{i},
$$

where $k=1,2, \ldots, n ; P_{i}$ denotes the net injection power of microgrid $i$; and sensitivity coefficient of microgrid $i$ injection power is represented by $C_{z s, i}$ :

$$
C_{z s, i}=\frac{\mathrm{d} L_{k}}{\mathrm{~d} P_{i}}=\frac{\left(\mathrm{d} \theta_{p} / \mathrm{d} P_{i}\right)-\left(\mathrm{d} \theta_{q} / \mathrm{d} L_{k}\right) P_{i}}{x_{k}}=\frac{X_{p i}-X_{q i}}{x_{k}},
$$

where $\theta_{p}$ and $\theta_{q}$ are phase angle of voltage at the beginning and end of branch $k$, respectively; $X_{p i}$ and $X_{q i}$ are impedance at the corresponding position in the impedance matrix in DC power flow, respectively; $x_{k}$ denotes the branch $k$ impedance.

After eliminating the line congestion, the net active power output of microgrid $i$ is reduced, which can be expressed as follows:

$$
\Delta P_{i}^{\mathrm{Up}}=C_{i} \Delta P_{\Sigma}^{\mathrm{Up}} .
$$

Here, microgrid $i$ power reduction scale factor is denoted by $C_{i}$.

Considering the confidence of microgrid historical information and the proportion of microgrid clean energy power generation, a model formula is established as follows:

$$
\left\{\begin{array}{l}
C_{i}=\alpha C_{\mathrm{zh}, i}+\beta C_{\mathrm{xn}, i}, \\
\sum_{i=1}^{n} C_{i}=1 .
\end{array}\right.
$$

Here, microgrid $i$ confidence assessment index is represented by $C_{z h, i} ;$ microgrid $i$ clean energy power generation ratio is denoted by $C_{\mathrm{xn}, i} ;$ and $\alpha$ and $\beta$ are the weighting factors.

\subsubsection{Calculation of Confidence Index of Active Net Output of} Microgrid. The confidence level of the microgrid affects the right to compete for rights when the resources of the distribution network are limited, that is, generating more credit and generating less credit. The confidence index depends on factors such as the actual active net output of the microgrid and the predicted net output interval, as shown in equations (11) and (12):

$$
C_{\mathrm{zh}, i}=\frac{1}{m \times t} \sum_{j=1}^{m} \sum_{k=1}^{t} \alpha_{i}^{j, k},
$$

where $C_{\mathrm{zh}, i}$ denotes reliability index of net output of microgrid $i$ and $m$ and $t$ are the number of days and the number of periods per day, respectively:

$$
\alpha_{i}=\frac{\sum_{\Delta \tau}\left(A \cap A^{\prime}\right)}{A \Delta t},
$$


where $A=\left[P_{i}^{\mathrm{Dn}}, P_{i}^{\mathrm{Up}}\right]$ is the prediction of the running interval of the forecast in the microgrid $i ; \alpha_{i}$ denotes interval confidence; the actual running interval of microgrid $i$ during $\Delta t$ period is denoted by $A^{\prime}=\left[P_{i}^{\mathrm{Dn} 1}, P_{i}^{\mathrm{Upl}}\right]$; actual cashed portion of forecast interval is represented by $A \cap A^{\prime} ; \Delta \tau$ denotes the confidence assessment sampling period; and $\Delta t$ is the predicted running interval time.

\subsubsection{Calculation of Proportion of Microgrid Clean Energy} Generation. Clean energy is widely accepted and meets the basic requirements of energy conservation and emission reduction in power grid. Therefore, when there is oversupply of multi-microgrid grid-connected output, the type of energy inside the microgrid should be considered, and certain priority should be given to clean energy. The index of microgrid clean energy power generation is shown in the following formula:

$$
C_{x n, i}=\frac{P_{x n, i}}{P_{i}^{\mathrm{Up}}}
$$

where $P_{x n, i}$ denotes the active output of clean energy in microgrid $i$ and $m$ and $n$ are the days and periods, respectively.

So far, for the development of a multi-microgrid selfregulatory space plan, this paper proposes the formulation process and method. On the basis of considering the problem of power flow congestion, the confidence degree including the historical information of microgrid and the proportion of clean energy generation in microgrid is proposed. The multi-microgrid prediction model of active net output reduction based on factors requires simulations of related examples to verify the effectiveness of the method.

\section{Simulation Example}

The test system for the distribution network is based on a three-phase balanced distribution network configuration with 33 buses (see Figure 6).

Bus 1 is connected to the uplink transmission grid. Branches 5-6, 13-14, 31-32, 8-21, 9-15, 12-22, 18-33, and 2529 are switchable lines. Branches 2-3, 9-10, and 29-30 have on-load tap changers, each of which has a tap between 0.95 and 1.05 ratios, with a single tap step of 0.025 . Buses 12,19 , and 28 are equipped with SVC (static reactive compensator), whose reactive power can be set to any value between $-300 \mathrm{kVar}$ and $900 \mathrm{kVar}$. Buses 13, 18, and 30 are microgrid buses.

The configuration of the basic case test system is shown (see Figure 6). The voltage value of bus 1 is kept at 1.0 p.u., the expected voltage value of all other buses is set at 1.0 p.u., and the actual value is allowed to vary between 0.9 p.u. and 1.1 p.u.

The active power and reactive power transmitted from each microgrid to the distribution network are limited in the range of $-500 \mathrm{~kW}$ to $500 \mathrm{~kW}$. The cost of inputting energy from the upstream transmission network through bus 1 is 88 $\$ / M W h$, the cost of reducing power demand on all buses is $500 \$ / \mathrm{MWh}$, and the factor of punishing voltage amplitude on all buses is $100 \$ / \mathrm{h}$. The basic values of power and voltage are set to $100 \mathrm{MVA}$ and $12.66 \mathrm{kV}$.

The characteristics of the controllable power generation units and energy storage devices installed in each microgrid, respectively, are shown in Tables 1 and 2.

The power requirements, renewable energy generation, and local reactive power output of each microgrid are shown in Table 3 .

The line impedance and load parameters are listed in Tables 4 and 5.

According to the method for formulating a multimicronet self-regulatory space plan, based on a 33-node example system, this section gives the results of the multimicronet self-regulatory space plan (see Table 6).

According to the abovementioned autonomous operation space formulation method, the intelligent distribution management system formulates the autonomous operation space for each microgrid. In the simulation results, the blue curve indicates the measured active power of each microgrid without constraints, the green band indicates the autonomous operation area, the yellow band indicates the coregulatory region, and the red band indicates the restricted operation area. It can be seen that in a day, the operation of microgrid 1 from 12:00 to 16:00 will affect the operation authority of other microgrids, and even when it exceeds the restricted operation area from 13:00 to 14:00, it will impact the whole distribution network operation. Microgrid 2 also exceeds the autonomous operation area from 0:00 to 3:00. The energy management system of microgrid 3 realizes the coordinated operation of source, load, and storage, so it can run completely autonomously. According to the self-discipline spatial plan issued by the distribution management system, each microgrid should respond positively; otherwise, it will directly affect its own economic interests (see Figure 7).

In order to clarify the idea of this article, the random operation point distribution of the multi-micronet in three cases is simulated to indicate the actual operation of the multi-micronet when executing the autonomous space plan. Microgrid 1 operates in the coordinated control area, and there is a certain difference between the actual active net output income and the expected net output income.

The net active power of microgrid 1 exceeds the physical constraint of distribution network when it operates in restricted area.

Microgrid 1 operates in the self-regulating operation area. The net active power has no effect on the operation of distribution network. Take microgrid 1 as an example, and the specific description is as follows (see Figure 8):

(1) During the [0:00-10:00] period, when microgrid 1 operates in the collaborative control area, there will be a certain difference between its active actual net output income and expected net output income. The main factors that affect the difference are as follows: the objective of distribution network optimization operation cost, the degree of privacy openness of microgrid (the storage capacity and quantity of distribution network adjustable sources, microgrid 


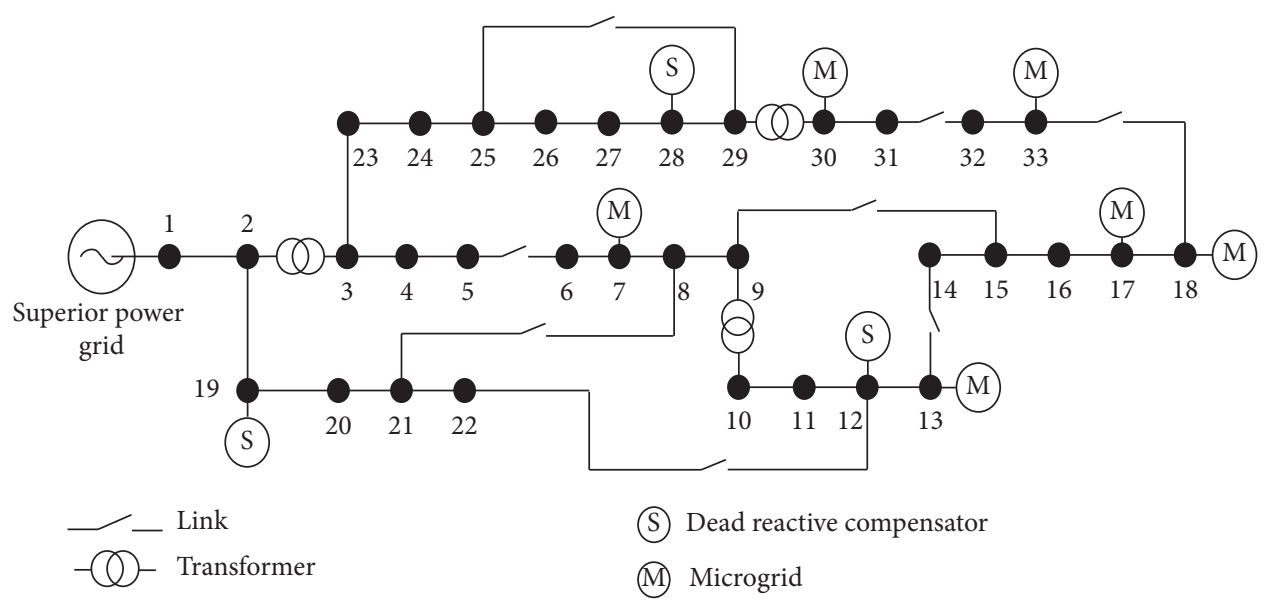

Figure 6: Diagram of the testing system.

TABLE 1: Controllable power generating units in 3 microgrids.

\begin{tabular}{|c|c|c|c|c|c|}
\hline \multirow{2}{*}{ Bus } & \multicolumn{2}{|c|}{ Technical parameters } & \multicolumn{3}{|c|}{ Cost coefficient } \\
\hline & Minimum delivered power $(\mathrm{kW})$ & Maximum delivered power $(\mathrm{kW})$ & $a(\$ /(\mathrm{MW}) 2 \mathrm{~h})$ & $b(\$ / \mathrm{MWh})$ & $c(\$ / \mathrm{h})$ \\
\hline 13 & 50 & 300 & 0.5 & 10 & 5 \\
\hline 18 & 100 & 500 & 1.2 & 15 & 3 \\
\hline 30 & 100 & 500 & 0.8 & 12 & 4 \\
\hline
\end{tabular}

TABLE 2: The parameters of energy storage devices in three microgrids.

\begin{tabular}{ccccccc}
\hline \multirow{2}{*}{ Bus } & Maximum power $(\mathrm{kW})$ & \multicolumn{3}{c}{ Energy level $(\mathrm{kWh})$} & Discharge/charge efficiency & Depreciation cost $(\$ /(\mathrm{MW})$ \\
& & Minimum & Maximum & Initial value & \\
\hline 13 & 50 & 50 & 200 & 100 & $0.9 / 0.9$ & 20 \\
18 & 100 & 100 & 300 & 100 & $0.9 / 0.9$ & 25 \\
30 & 100 & 100 & 300 & 200 & $0.85 / 0.85$ & 15 \\
\hline
\end{tabular}

TABLE 3: Local loads and other energy parameters of three microgrids.

\begin{tabular}{cccccc}
\hline \multirow{2}{*}{ Bus } & \multicolumn{2}{c}{ Power demand } & \multicolumn{2}{c}{ Renewable energy sources $(\mathrm{kW})$} & \multicolumn{2}{c}{ Reactive power output } \\
& Active $(\mathrm{kW})$ & Reactive $(\mathrm{kVar})$ & & -100 & Minimum $(\mathrm{kVar})$ \\
\hline 13 & 350 & 200 & $0.9 / 0.9$ & -250 & 500 \\
18 & 400 & 300 & $0.9 / 0.9$ & -200 & 750 \\
30 & 500 & 800 & $0.85 / 0.85$ & 600 \\
\hline
\end{tabular}

cost information, microgrid operation information, etc.), and the participation of distribution market bidding and so on.

(2) During the period [11:00-15:00], microgrid 1 operates in the restricted area, and its net active power exceeds the physical constraints of the distribution network. The distribution network has the right to take coercive measures to limit its power generation behavior and count its out of bounds. The data are processed in a punishment mechanism.

(3) During the [16:00-23: 00] period, microgrid 1 operates in the self-regulated operating area. The amount of its net active power has no effect on the operation of the distribution network. It can be allowed to operate completely autonomously, and statistics of its operating data are included bonus system.

According to the method of making autonomous spatial planning of multi-microgrid mentioned above, the results of autonomous spatial planning of multi-microgrid are given based on a 33-node example system (see Figure 9). It is not difficult to find that the confidence assessment index of microgrid 1 is lower than that of microgrid 2 and microgrid 3, and the proportion index of clean energy generation is the same as microgrid 2, but lower than microgrid 3. Therefore, when microgrid 1 has limited power demand in the distribution network and needs to reduce the active net output of each microgrid, the active output reduction share of its upward grading network forecast is larger. Microgrid 3 has better confidence assessment index and clean energy power generation 
TABLE 4: Line impedance of 33-node system.

\begin{tabular}{|c|c|c|c|c|c|c|c|}
\hline Initial node & Final node & $\begin{array}{l}\text { Line resistance } \\
\text { (p.u.) }\end{array}$ & $\begin{array}{c}\text { Line reactance } \\
\text { (p.u.) }\end{array}$ & Initial node & Final node & $\begin{array}{c}\text { Line resistance } \\
\text { (p.u.) }\end{array}$ & $\begin{array}{c}\text { Line reactance } \\
\text { (p.u.) }\end{array}$ \\
\hline 1 & 2 & 0.057526 & 0.029324 & 3 & 23 & 0.281515 & 0.192356 \\
\hline 3 & 4 & 0.228357 & 0.116300 & 23 & 24 & 0.560285 & 0.442425 \\
\hline 4 & 5 & 0.237778 & 0.121104 & 24 & 25 & 0.559037 & 0.437434 \\
\hline 5 & 6 & 0.510995 & 0.441115 & 6 & 26 & 0.126657 & 0.064514 \\
\hline 6 & 7 & 0.116799 & 0.386085 & 26 & 27 & 0.177320 & 0.090282 \\
\hline 7 & 8 & 0.443860 & 0.146685 & 27 & 28 & 0.660737 & 0.582559 \\
\hline 8 & 9 & 0.642643 & 0.461705 & 28 & 29 & 0.501761 & 0.437122 \\
\hline 10 & 11 & 0.122664 & 0.040555 & 30 & 31 & 0.607953 & 0.600840 \\
\hline 11 & 12 & 0.233598 & 0.077242 & 31 & 32 & 0.193729 & 0.225799 \\
\hline 12 & 13 & 0.915922 & 0.720634 & 32 & 33 & 0.212759 & 0.330805 \\
\hline 13 & 14 & 0.337918 & 0.444796 & 21 & 8 & 1.247851 & 1.247851 \\
\hline 14 & 15 & 0.368740 & 0.328185 & 9 & 15 & 1.247851 & 1.247851 \\
\hline 15 & 16 & 0.465635 & 0.340039 & 12 & 22 & 1.247851 & 1.247851 \\
\hline 16 & 17 & 0.804240 & 1.073775 & 18 & 33 & 0.311963 & 0.311963 \\
\hline 17 & 18 & 0.456713 & 0.358133 & 25 & 29 & 0.311963 & 0.311963 \\
\hline 2 & 19 & 0.102324 & 0.097644 & 2 & 34 & 0.307595 & 0.156668 \\
\hline 19 & 20 & 0.938508 & 0.845668 & 9 & 35 & 0.651378 & 0.461705 \\
\hline 20 & 21 & 0.255497 & 0.298486 & 29 & 36 & 0.316642 & 0.161285 \\
\hline 21 & 22 & 0.442301 & 0.584805 & - & - & - & - \\
\hline
\end{tabular}

TABLE 5: Load power of 33-node system.

\begin{tabular}{|c|c|c|c|c|c|}
\hline Node number & Active $(\mathrm{kW})$ & Reactive (kVar) & Node number & Active $(\mathrm{kW})$ & Reactive (kVar) \\
\hline 2 & 90 & 40 & 19 & 90 & 40 \\
\hline 3 & 120 & 80 & 20 & 90 & 40 \\
\hline 4 & 60 & 30 & 21 & 90 & 40 \\
\hline 5 & 60 & 20 & 22 & 90 & 40 \\
\hline 6 & 200 & 100 & 23 & 90 & 50 \\
\hline 7 & 200 & 100 & 24 & 420 & 200 \\
\hline 8 & 60 & 20 & 25 & 420 & 200 \\
\hline 9 & 60 & 20 & 26 & 60 & 25 \\
\hline 10 & 45 & 30 & 27 & 60 & 25 \\
\hline 11 & 60 & 35 & 28 & 60 & 20 \\
\hline 12 & 350 & 200 & 29 & 120 & 70 \\
\hline 13 & 120 & 80 & 30 & 500 & 800 \\
\hline 14 & 60 & 10 & 31 & 150 & 70 \\
\hline 15 & 60 & 20 & 32 & 210 & 100 \\
\hline 16 & 60 & 20 & 33 & 60 & 40 \\
\hline 17 & 100 & 60 & - & - & - \\
\hline
\end{tabular}

proportion index than microgrid 1 and microgrid 2, so its active power reduction share of upward grading network forecast is small. It should be pointed out that in different periods of a day, the higher-level distribution network can reasonably allocate the weight coefficients of confidence assessment indicators and clean energy power generation proportion indicators according to the load power demand information.

In summary, the formulation of a self-regulatory space plan divides an unconstrained multi-microgrid into three areas, namely, a restricted area, a coordinated regulatory area, and a self-regulated operating area. In the self-disciplined operating area, microgrids can operate in a completely autonomous manner without restriction. The restricted area strictly stipulates the bottom line of the operation boundary of each microgrid. When the control strategy of microgrid exceeds the restricted area, the distribution network has the right to take standby restrictive measures according to the agreement. For microgrids operating in the coordinated regulatory area, the distribution network needs to adopt coordinated control methods. In accordance with the changing operating scenarios, the coordinated regulatory area is used to define an operating area on the basis of fair distribution of win-win space for all parties.

The distribution network will treat the multi-microgrids whose operating points are in the restricted area and the self-regulated operating area, and include their operating information into the reward and punishment mechanism under the cooperative self-regulatory control 
TABLE 6: Self-disciplinary space planning for multi-microgrids.

\begin{tabular}{|c|c|c|c|}
\hline \multirow{2}{*}{ Time } & \multicolumn{3}{|c|}{ Self-disciplinary space planning $(\mathrm{kW})$} \\
\hline & Microgrid 1 & Microgrid 2 & Microgrid 3 \\
\hline 1 & {$[94.99,310.88]$} & {$[94.99,370.88]$} & {$[194.99,560.88]$} \\
\hline 2 & {$[112.22,358.48]$} & {$[112.22,368.48]$} & {$[212.22,608.48]$} \\
\hline 3 & {$[107.95,380.32]$} & {$[107.95,384.32]$} & {$[207.95,610.32]$} \\
\hline 4 & {$[102.92,377.99]$} & {$[102.92,377.99]$} & {$[202.92,607.99]$} \\
\hline 5 & {$[113.07,330.56]$} & {$[113.07,390.56]$} & {$[213.07,580.56]$} \\
\hline 6 & {$[137.04,427.56]$} & {$[137.04,400.59]$} & {$[237.04,647.56]$} \\
\hline 7 & {$[149.49,410.87]$} & {$[149.49,410.87]$} & {$[249.49,630.87]$} \\
\hline 8 & {$[121.56,420.45]$} & {$[121.56,419.15]$} & {$[211.51,632.87]$} \\
\hline 9 & {$[133.54,385.66]$} & {$[133.54,375.64]$} & {$[233.54,635.66]$} \\
\hline 10 & {$[133.07,390.89]$} & {$[133.07,384.89]$} & {$[233.07,640.89]$} \\
\hline 11 & {$[105.47,346.33]$} & {$[105.47,366.33]$} & {$[205.47,596.33]$} \\
\hline 12 & {$[102.22,287.99]$} & {$[102.22,377.99]$} & {$[202.22,537.99]$} \\
\hline 13 & {$[101.94,321.44]$} & {$[101.94,361.44]$} & $201.94,571.44]$ \\
\hline 14 & {$[87.99,330.35]$} & {$[87.99,330.35]$} & {$[187.99,580.35]$} \\
\hline 15 & {$[77.49,290.12]$} & {$[77.49,310.12]$} & {$[177.49,540.12]$} \\
\hline 16 & {$[76.99,270.45]$} & {$[76.99,310.45]$} & {$[176.99,520.45]$} \\
\hline 17 & {$[63.99,295.44]$} & {$[63.99,285.44]$} & {$[163.99,545.44]$} \\
\hline 18 & {$[52.49,276.88]$} & {$[52.49,279.88]$} & {$[152.49,526.88]$} \\
\hline 19 & {$[67.99,261.22]$} & {$[67.99,251.75]$} & {$[167.99,511.22]$} \\
\hline 20 & {$[42.49,286.79]$} & {$[42.49,286.79]$} & {$[142.49,536.79]$} \\
\hline 21 & {$[72.99,288.78]$} & {$[72.99,297.78]$} & {$[172.99,538.78]$} \\
\hline 22 & {$[83.49,307.97]$} & {$[83.49,307.97]$} & {$[183.49,557.97]$} \\
\hline 23 & {$[86.99,330.43]$} & {$[86.99,300.43]$} & {$[186.99,580.43]$} \\
\hline 24 & {$[74.49,368.89]$} & {$[74.49,318.89]$} & {$[174.49,618.89]$} \\
\hline
\end{tabular}

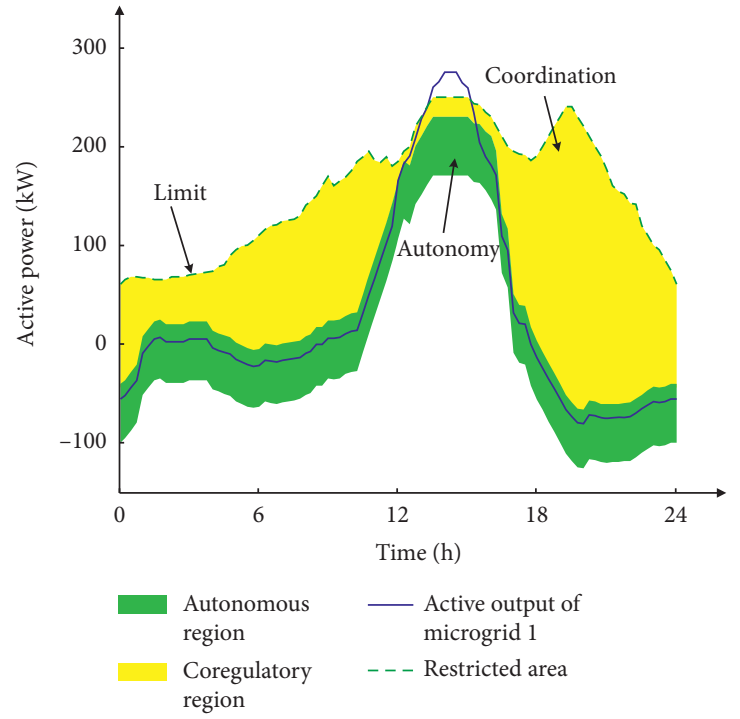

(a)

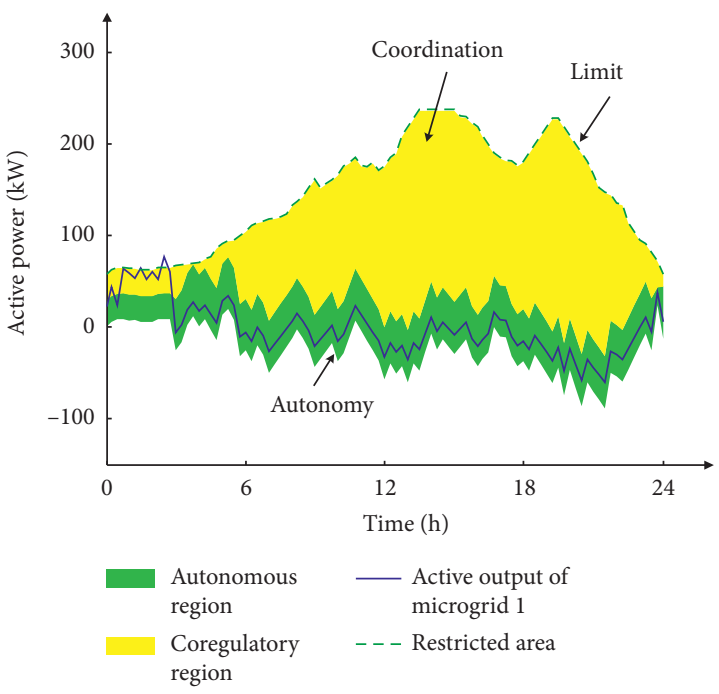

(b)

FIgURE 7: Continued. 


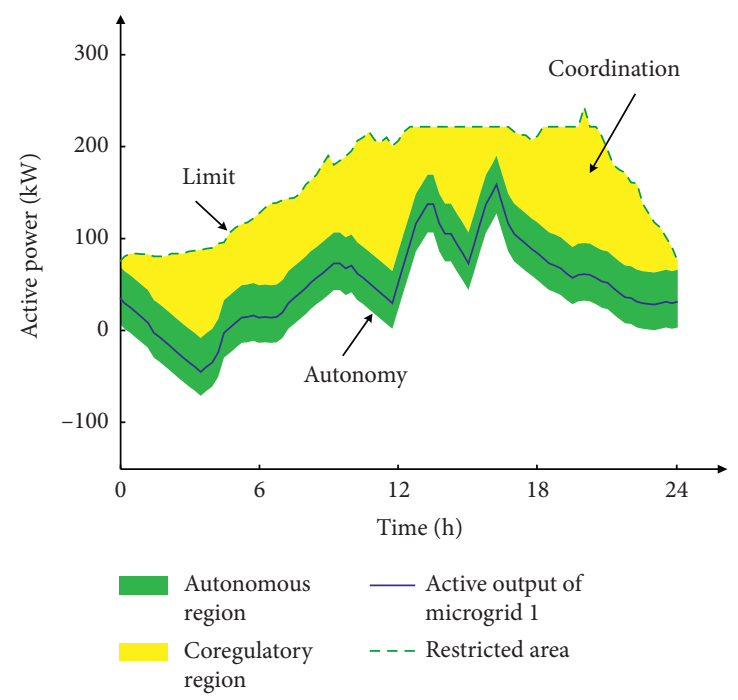

(c)

Figure 7: Autonomous operation space designated by the distribution management system for each microgrid: autonomous running space of (a) microgrid 1, (b) microgrid 2, and (c) microgrid 3.

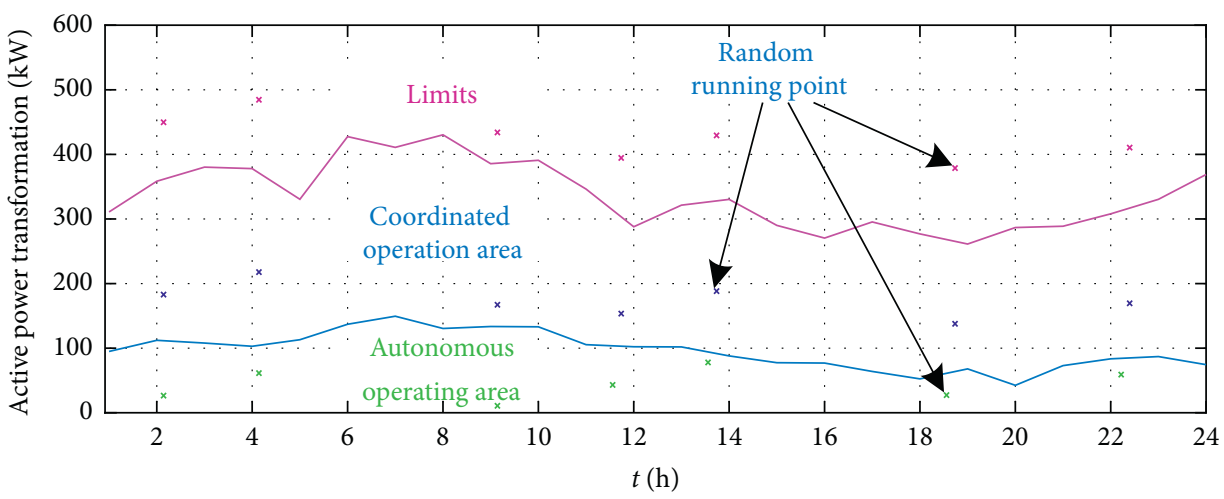

(a)

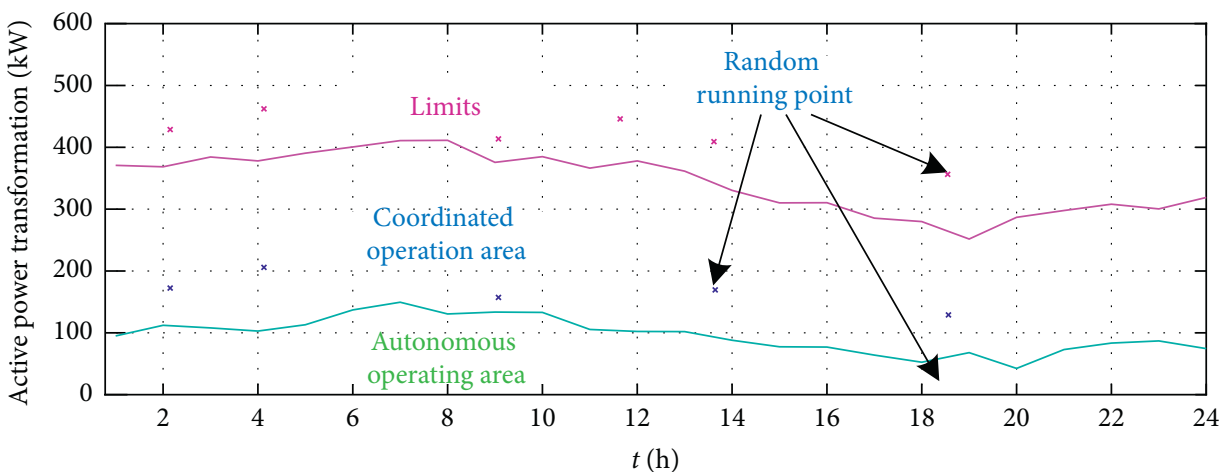

(b)

Figure 8: Continued. 


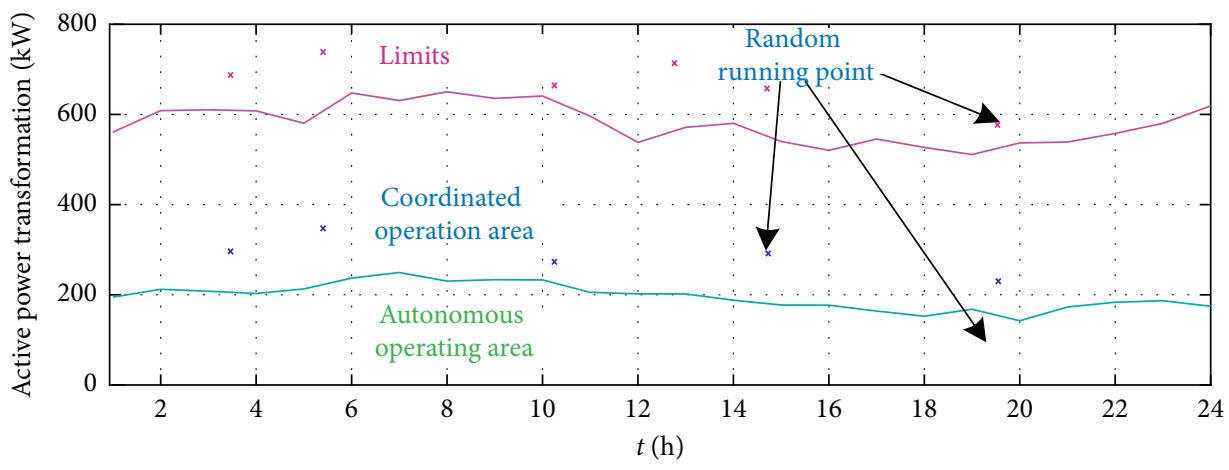

(c)

FIGURE 8: Self-disciplinary operation interval of each microgrid designated by distribution network management system. (a) Microgrid 1 self-disciplinary operation interval, (b) microgrid 2 self-disciplinary operation interval, and (c) Microgrid 3 self-disciplinary operation interval.

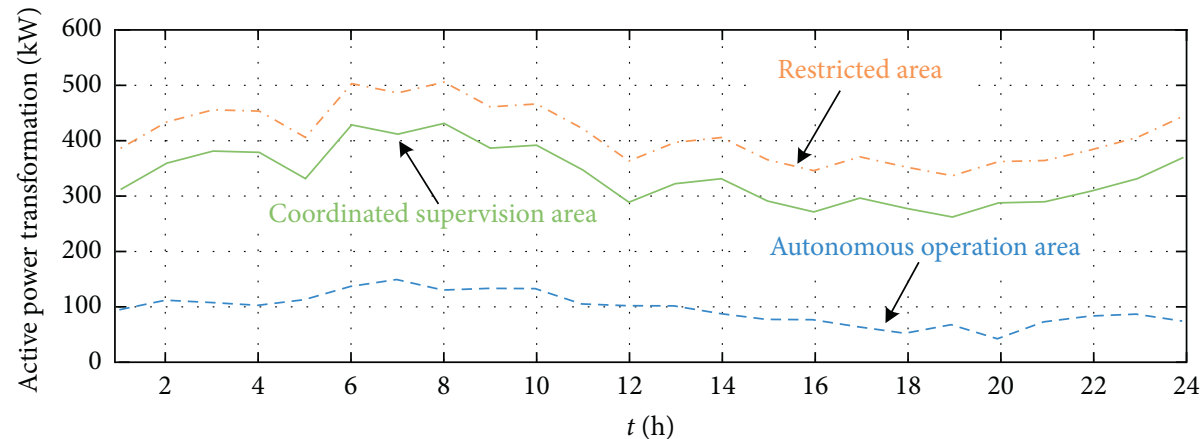

(a)

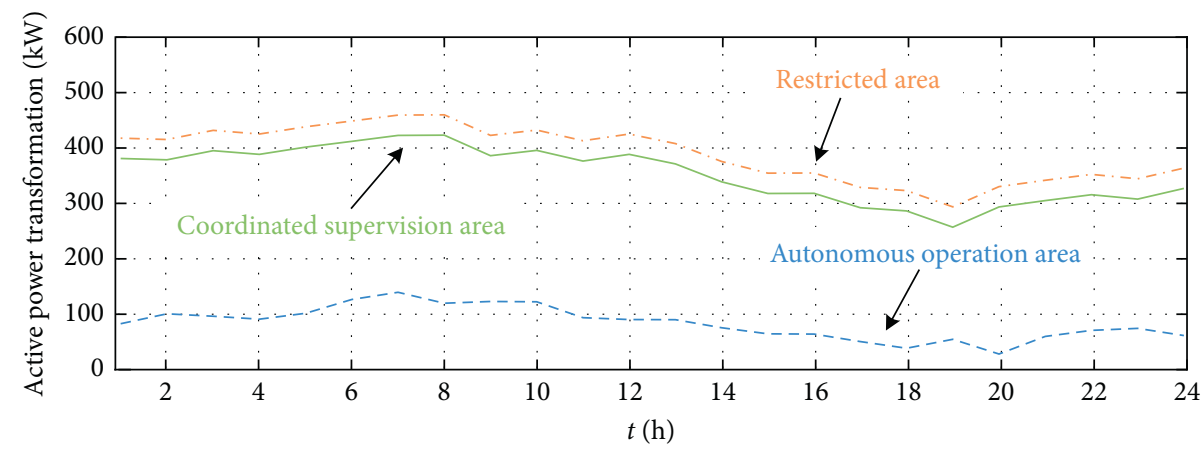

(b)

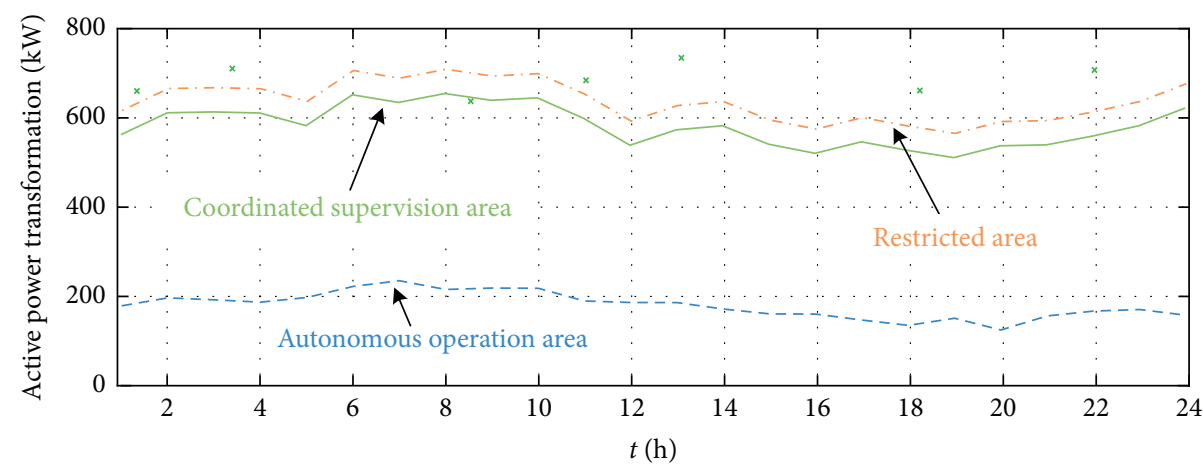

(c)

FiguRE 9: Self-disciplined operation space plan designated by the distribution management system for each microgrid. (a) Boundary of each region in microgrid 1, (b) boundary of each region in microgrid 2, and (c) boundary of each region in microgrid 3. 
mode. Different reward and punishment efforts under the reward and punishment mechanism will effectively induce the profit of multi-microgrid operation behavior, forcing each microgrid to pay more attention to the accuracy of its energy management system's prediction of power generation behavior, which is conducive to the formulation and implementation of autonomous space plans.

\section{Conclusion}

This article proposes the basic framework of the cooperative self-regulatory operation mode and elaborates the concept, characteristics, framework system, decision-making process, and supporting rewards and punishment mechanisms of the cooperative self-regulatory regulation mode. Network operation behavior is guided and restricted by space plans and reward and punishment mechanisms such as restricted zones, coordinated control zones, and self-regulatory operating zones. Simulation results verify the effectiveness of the proposed method. The establishment of a multimicrogrid self-regulatory operation space plan under the coordinated self-regulatory control mode has greatly reduced the regulation dimension and control time of the distribution network and improved the initiative and flexibility of the multi-microgrid participation in distribution operation.

\section{Data Availability}

The data used to support the findings of this study are included within the article.

\section{Conflicts of Interest}

The authors declare that they have no conflicts of interest.

\section{References}

[1] W. Yang, L. Cheng, N. Qi, Y. Liu, and X. Wang, "Review on distribution network planning methods considering largescale access of flexible load," in Proceedings of the 2018 2nd IEEE Conference on Energy Internet and Energy System Integration (EI2), IEEE, Beijing, China, October 2018.

[2] S. M. Mirbagheri, D. Falabretti, and M. Merlo, "Voltage control in active distribution grids: a review and a new set-up procedure for local control laws," in Proceedings of the 2018 International Symposium on Power Electronics, Electrical Drives, Automation and Motion (SPEEDAM), pp. 1203-1208, IEEE, Amalfi, Italy, June 2018.

[3] J. Ding, K. Wang, J. Y. Wu, F. Ma, and C. L. Ma, "Reliability analysis and optimization configuration of distribution network based on autonomous control unit," in Proceedings of the 2018 China International Conference on Electricity Distribution (CICED), pp. 883-887, Tianjin, China, September 2018.

[4] X. Bai, Y. Mavrocostanti, D. Strickland, and C. Harrap, "“Distribution network reconfiguration validation with uncertain loads-network configuration determination and application," IET Generation, Transmission \& Distribution, vol. 11, no. 2, p. 582, 2017.
[5] H. M. A. Ahmed, A. B. Eltantawy, and M. M. A. Salama, "A planning approach for the network configuration of AC-DC hybrid distribution systems," IEEE Transactions on Smart Grid, vol. 9, no. 3, pp. 2203-2213, 2018.

[6] P. C. Loh, D. Li, Y. K. Chai, and F. Blaabjerg, "Autonomous control of interlinking converter with energy storage in hybrid AC-DC microgrid," IEEE Transactions on Industry Applications, vol. 49, no. 3, pp. 1374-1382, 2013.

[7] A. Gupta, S. Doolla, and K. Chatterjee, "Hybrid AC-DC microgrid: systematic evaluation of control strategies," IEEE Transactions on Smart Grid, vol. 9, no. 4, pp. 3830-3843, 2018.

[8] L. Che, M. Shahidehpour, A. Alabdulwahab, and Y. Al-Turki, "Hierarchical coordination of a community microgrid with AC and DC microgrids," IEEE Transactions on Smart Grid, vol. 6, no. 6, pp. 3042-3051, 2015.

[9] M. M. Esfahani, A. Hariri, and O. A. Mohammed, "A multiagent-based game-theoretic and optimization approach for market operation of multimicrogrid systems," IEEE Transactions on Industrial Informatics, vol. 15, no. 1, pp. 280-292, 2019.

[10] R. Mohammadi, H. R. Mashhadi, and M. Shahidehpour, "Market-based customer reliability provision in distribution systems based on game theory: a Bi-level optimization approach," IEEE Transactions on Smart Grid, vol. 10, no. 4, pp. 3840-3848, 2019.

[11] M. H. S. Boloukat and A. A. Foroud, "Multiperiod planning of distribution networks under competitive electricity market with penetration of several microgrids, part I: modeling and solution methodology," IEEE Transactions on Industrial Informatics, vol. 14, no. 11, pp. 4884-4894, 2018.

[12] M. H. S. Boloukat and A. A. Foroud, "Multiperiod planning of distribution networks under competitive electricity market with penetration of several microgrids part II: case study and numerical analysis," IEEE Transactions on Industrial Informatics, vol. 15, no. 4, pp. 2023-2031, 2019.

[13] H. Farzin, M. Fotuhi-Firuzabad, and M. Moeini-Aghtaie, "Reliability studies of modern distribution systems integrated with renewable generation and parking lots," IEEE Transactions on Sustainable Energy, vol. 8, no. 1, pp. 431-440, 2017.

[14] U. Firdaus and O. Penangsang, "Economic dispatch of multi microgrid systems with renewable energy sources using particle swarm optimization," in Proceedings of the 2016 International Seminar on Intelligent Technology and Its Applications (ISITIA), pp. 595-600, Lombok, Indonesia, July 2016.

[15] J. S. Ren, K. T. Tan, B. Sivaneasan, P. L. So, and E. Gunawan, "Energy management of a multi-agent based multi-microgrid system," in Proceedings of the 2014 IEEE PES Asia-Pacific Power and Energy Engineering Conference (APPEEC), Hong Kong, China, December 2014.

[16] X. Dou, P. Xu, Q. Hu et al., "A distributed voltage control strategy for multi-microgrid active distribution networks considering economy and response speed," IEEE Access, vol. 6, pp. 31259-31268, 2018.

[17] Q. Shafiee, T. Dragicevic, J. C. Vasquez, and J. M. Guerrero, "Hierarchical control for multiple DC-microgrids clusters," IEEE Transactions on Energy Conversion, vol. 29, no. 4, pp. 922-933, 2014.

[18] Y. Han, H. Li, P. Shen, E. A. A. Coelho, and J. M. Guerrero, "Review of active and reactive power sharing strategies in hierarchical controlled microgrids," IEEE Transactions on Power Electronics, vol. 32, no. 3, pp. 2427-2451, 2017.

[19] N. J. Gil and J. A. P. Lopes, "Hierarchical frequency control scheme for islanded multi-microgrids operation," in 
Proceedings of the 2007 IEEE Lausanne Power Tech, pp. 473-478, Lausanne, Switzerland, July 2007.

[20] M. S. Alam and S. A. Arefifar, "Energy management in power distribution systems: review, classification, limitations and challenges," IEEE Access, vol. 7, pp. 92979-93001, 2019.

[21] H. Farzin, M. Fotuhi-Firuzabad, and M. Moeini-Aghtaie, "Role of outage management strategy in reliability performance of multi-microgrid distribution systems," IEEE Transactions on Power Systems, vol. 33, no. 3, pp. 2359-2369, 2018.

[22] V. Telukunta, J. Pradhan, J. Pradhan, A. Singh, and S. G. Srivani, "Protection challenges under bulk penetration of renewable energy resources in power systems: a review," CSEE Journal of Power and Energy Systems, vol. 3, no. 4, pp. 365379, 2017.

[23] A. Keane, L. F. Ochoa, C. L. T. Borges et al., "State-of-the-Art techniques and challenges ahead for distributed generation planning and optimization," IEEE Transactions on Power Systems, vol. 28, no. 2, pp. 1493-1502, 2013.

[24] X. Li, L. Guo, Y. Li et al., "Flexible interlinking and coordinated power control of multiple DC microgrids clusters," IEEE Transactions on Sustainable Energy, vol. 9, no. 2, pp. 904-915, 2018.

[25] L. Wang, F. Bai, R. Yan, and T. K. Saha, "Real-time coordinated voltage control of PV inverters and energy storage for weak networks with high PV penetration," IEEE Transactions on Power Systems, vol. 33, no. 3, pp. 3383-3395, 2018.

[26] Z. Li, M. Shahidehpour, F. Aminifar, A. Alabdulwahab, and Y. Al-Turki, "Networked microgrids for enhancing the power system resilience," Proceedings of the IEEE, vol. 105, no. 7, pp. 1289-1310, 2017.

[27] Z. Li, M. Shahidehpour, A. Alabdulwahab, and A. Abusorrah, "Bilevel model for analyzing coordinated cyber-physical attacks on power systems," IEEE Transactions on Smart Grid, vol. 7, no. 5, pp. 2260-2272, 2016.

[28] M. E. Baran and F. F. Wu, "Network reconfiguration in distribution systems for loss reduction and load balancing," IEEE Transactions on Power Delivery, vol. 4, no. 2, pp. 14011407, 1989.

[29] W. Wu, Z. Tian, and B. Zhang, "An exact linearization method for oltc of transformer in branch flow model," IEEE Transactions on Power Systems, vol. 32, no. 3, pp. 2475-2476, 2017.

[30] Y. Li, C. L. Wang, G. Q. Li et al., "Improving operational flexibility of integrated energy system with uncertain renewable generations considering thermal inertia of buildings," Energy Conversion and Management, vol. 207, 2020.

[31] Y. Li, Z. Yang, G. Li, D. Zhao, and W. Tian, "Optimal scheduling of an isolated microgrid with battery storage considering load and renewable generation uncertainties," IEEE Transactions on Industrial Electronics, vol. 66, no. 2, pp. 1565-1575, 2019.

[32] Y. Li, B. Feng, G. Li, J. Qi, D. Zhao, and Y. Mu, "Optimal distributed generation planning in active distribution networks considering integration of energy storage," Applied Energy, vol. 210, pp. 1073-1081, 2018. 